This is an Accepted Manuscript of an article published by Taylor \& Francis in Development and Practice on 6 June 2012, available online: http://www.tandfonline.com/doi/pdf/10.1080/09614524.2012.672955

Published as:

Morrow, Virginia and Uma Vennam (2012) “Children's responses to risk in agricultural work in Andhra Pradesh, India", Development in Practice 22 (4): 549-561. DOI:

$10.1080 / 09614524.2012 .672955$

The article is reproduced in accordance with the self-archiving policies of Taylor \& Francis. 


\title{
Children's responses to risk in agricultural work in Andhra Pradesh, India.
}

\section{Virginia Morrow and Uma Vennam}

\begin{abstract}
This paper discusses protection of children from hazards in agricultural work. International and national policies aim to protect children by eliminating all child labour. Previous literature on hazardous child labour tends to focus on single industries or crops, overlooking the variety of activities that children undertake in subsistence farming. We analyse survey and qualitative data from children, and present rates of work, injuries experienced, how children deal with risks, and perceived benefits of work. The most effective form of prevention may be to build on existing knowledge and experience, working with communities to develop strategies to make work safer.
\end{abstract}

\section{Introduction}

This paper contributes research on hazardous child labour in agriculture, by foregrounding children's accounts. Agriculture is the largest sector of the economy in which children work (Fassa et al. 2010). According to the International Labour Organisation (ILO), an estimated 60 per cent of all child workers engage in agriculture (ILO 2010). Children who live on farms undertake numerous tasks related to agricultural production, in various forms of economic relationship, from family-based subsistence farming to commercial plantations, in developed and in developing countries. Some of these tasks inevitably involve physical risks and potential harm. Yet agricultural work within families tends to fall outside national and international definitions of child labour, and in many countries is unregulated.

Much research on child labour, and consequent policy initiatives, are based on the assumption that children are passive victims requiring protection from labour, that poverty causes child labour, and that children are compelled to work by their parents. In the literature on hazardous child labour, there has been a tendency to focus on single industries or specific crops like cotton seed or cocoa, which misses the variety of activities that children undertake, particularly in subsistence and market farming. The existing literature rarely acknowledges that children learn through experience not only to work, but may also learn to manage harm associated with work. Further, children persistently work and sometimes want to work (Bourdillon et al. 2010). Why is this? Are campaigns against child labour overlooking the fundamental place of work in children's lives? What is lost when children are removed from work? Very little research has explored what children themselves say about hazards they encounter at work, nor how they try to perhaps manage these risks (Abebe and Bessell 2011).

In response to these questions, we draw on survey data from Young Lives in Andhra Pradesh (see preface to this volume). The paper also draws qualitative data from 42 children, collected for a sub-study. 
This paper does not discuss whether children should be allowed to work or be pushed to work. Nor do we attempt to determine whether agricultural child labour should be classified as 'hazardous' work, and we do not draw on objective measurements of possible effects of work on health, which are problematic (see Levison and Murray-Close 2005; Fassa et al. 2010). We demonstrate how children perceive their work, and how they attempt to protect themselves at work. We suggest that more could be done to work with communities, while agriculture remains at a low level of technological development and demands hard manual labour. The paper raises questions about child protection strategies that focus solely on children's work in situations of rural poverty, such as those proposed by the ILO (ILO 2011), where families face a number of threats to general health, and suggests that greater attention be paid to how communities already attempt to protect themselves.

The next section of the paper describes recent efforts to protect children from hazardous work at international and national policy level in India. The third section describes a small-scale study that explored children's experiences of work in two communities in Andhra Pradesh, India. The final section explores the fits and misfits between international aspirations and the micro-level of children's lived realities.

\section{The background of international and national policy}

What are the key current international and national policies that attempt to protect children by controlling hazardous child labour? In May 2010, the ILO held a Global Conference entitled 'Towards a world without child labour'. The meeting agreed a 'Road Map' towards the elimination of the worst forms of child labour by 2016, in line with the two main ILO Conventions relating to child labour, Convention 138, on the minimum age for work, and Convention 182 (and related Recommendation 190). The latter prohibits 'worst forms of child labour', which include 'work which ... is likely to harm the health, safety or morals of children' (Art 3, d). States define 'hazardous' work, but this is problematic, since 'hazardous work' lists are often borrowed from other countries, may be out-of-date, or tackle obviously hazardous work, such as mining, but not hazardous tasks found in agriculture (ILO 2011: 42). India has taken up this global campaign, yet has not set a general minimum age for all work, and sets a low age (14 years) for work categorised as hazardous. India has not ratified ILO conventions 138 and 182 (Ramanathan 2000). The Child Labour (Prohibition and Regulation) Act 1986 prohibits the employment of children in certain occupations and processes, but does not address family-based labour. A range of national policy interventions and proposals are currently relevant, including the Right of Children to Free and Compulsory Education Act (2009) (RTE), intended to guarantee access to primary 
education from the ages of 5 to 14 years. There are campaigns by NGOs (for example, Save the Children India, CRY) to include agricultural labour in the list of 'hazardous work'. There are initiatives to eliminate child labour, including recourse to the law to 'rescue and rehabilitate' bonded child labourers. However, prosecutions of employers are rare, and none of the legislation relates to children working with their families in agriculture. International and state level policies can seem remote from the everyday lives of children in rural areas.

Large numbers of children work in India, especially in agriculture (Subbaraman and von Witzke 2007). Children's roles and activities are structured by caste, ethnicity and religion (see Gupta 2005).

Historically, children took up the roles of their parents, working alongside them from an early age. Shirol (2000) in an ethnography in rural Karnataka conducted in the late 1980s, described the relationship between social organisation and children's work linked to the caste system. Higher caste children typically worked to inherit traditional occupations rather than for wages. Lower caste children worked mainly for wages with less emphasis on developing traditional occupations. The Government of India has introduced numerous policy initiatives to try to reduce discrimination and the effects of caste/ethnicity on children's life chances.

Evidence shows that current policies are not effective and large numbers of children continue to work (ILO 2011). We suggest that incorporating children's views about their work could enrich understanding and practice in this area. To do so would be in line with Recommendation 190 (Section 1, Para 2) of ILO Convention 182, which suggests that programmes of action should be designed 'in consultation with relevant government institutions and employers' and workers' organisations', taking into consideration the views of the children directly affected by the worst forms of child labour, their families and, as appropriate, other concerned groups...' (emphasis added).

\section{Children's experiences of work}

The next section of the paper briefly presents some findings from the Young Lives survey, before presenting findings from qualitative research relating to risks/harms at work.

\section{How many children are working?}

Young Lives collects data from 2,000 children born in 2000-1 (the younger cohort) and 1,000 children in each country born in 1994-5 (the older cohort). There have been three rounds of survey data collection in Andhra Pradesh, with the third conducted in 2009. Information on child work comes from two components of the survey, a set of questions asking children about the amount of time spent on various 
tasks in a 'typical day' in the week preceding the survey, and a question that asks whether children have done any paid work in the previous 12 months. There is a fairly strong correspondence between answers to these. Analysis uses paid work on a typical day, paid or unpaid work for the household (such as farm labour, but excluding domestic chores), and doing any paid work in the previous 12 months. The percentage of older cohort children who were in paid and unpaid work rose from 6 per cent in Round 1 (2002, when the children were aged 7-8 years) to 22 per cent in Round 2 (2006-7, when they were 12) to 28 per cent in 2009 (when they were 14-15). In 2009, 33 per cent of children reported work in rural areas compared to 12 per cent in urban areas, reflecting the dominance of agricultural activities in rural children's lives. However, the time-use question may underestimate the extent of children's work, because in rural households the distinction between domestic labour and unpaid work is hazy: for some children, cattle grazing may be seen as a household chore.

By the time children reach secondary school age, many of them are expected to engage in work at home and on farms, especially during the peak agricultural seasons. Some children manage school, home and farm work in complex ways (Morrow and Vennam 2010). Children's work needs to be seen in the context of local understandings of childhood, expectations about children's roles and responsibilities, and the contributions that children make to their families. A complex mix of factors, including poverty, gender, caste, ethnicity, parental ill-health, and attitudes to work, appear to intersect to explain why children work. Far from passively being put to work, some children make active decisions to help the family situation by working.

\section{Qualitative research with children}

Using an analysis of survey data from Young Lives, two rural sites were identified as having relatively high rates of older cohort children involved in agricultural wage labour. The study explored the following questions. First, what are children's understandings of 'risks' at work? Second, what are children's experiences of managing risks they face at work?

Children engaged in agricultural work, either on their own farms or for wages, were invited to take part. Methods were adapted from Woodhead's (1999) study of the psychosocial consequences of children's work in six countries, using activities and questions designed to elicit how children perceive their work. Interviews were conducted with children, exploring their experiences of work, time use and responsibilities, managing risks, and what they perceived might be the risks in stopping children from working. The interviews included 'body mapping', a visual method using a large sheet of paper with the 
outline of a body that enables children to identify parts of the body affected by work. This is a recognised method for eliciting people's experiences of health and harm (see Cornwall 1992, Clacherty 2009). Group discussions explored children's daily lives, time use, good and bad aspects of work, school, combining work and school, which work is best, and at what age childhood begins and ends in relation to different tasks. Group discussions with caregivers focussed on community norms affecting children's activities, risks to children and how they manage them, and variations according to gender, age, birth order, and caste. Children and adults gave consent. Fieldwork was conducted in Spring 2011, and fieldwork teams spent about 10 days in each site.

We use pseudonyms for the two sites. Avanti is in Rayalaseema, where the main crops are paddy, sunflower, sesame, millet, cotton, sweet-lime, lime and mango. Children work most frequently in the sweet-lime groves, with work in lemon groves being the next most common. 21 children aged 15-16 years were interviewed, 11 girls and 10 boys. Compulsory education lasts until age 14 in India, and most of them were in full-time work, although three boys were combining school and work. Most were from Scheduled Castes or Backward Castes [see endnote]. Bhakrapet is in Telangana region of the state. Crops are paddy, chillies, and cotton. Children are involved in herding livestock, involving stays of 2-3 months in the forest while they graze cows and sheep. Children also work in chilli and cotton farming (not for seed). 21 children were interviewed, 10 boys and 11 girls (11 were from Scheduled Castes, five from Backward Castes, and five from Scheduled Tribes). Three group activities were held with boys, three with girls, and an individual interview was held with sarpanch, (elected head of the village-level self-governing council) and two collective interviews were held with caregivers.

\section{Why children work:}

There are a number of factors that explain why children work. First, poverty or specific household situations may leave children with little choice about work. They engage in work in different crops, and finding work is important to them. Second, according to children, parents think that children are ready to work as they turn twelve years old. Once they enter work, they continue to work, and this gradually becomes their occupation. This work prepares them for the future. Children from not-so-poor households who have left school take up work on the farms on the days that they like to work, and have some control over their earnings. These children prefer to work with groups of friends and look for fun and enjoyment while working, despite the physical demands of work. Children describe using their earnings to buy clothes, footwear, CDs, mobile phone maintenance, jewellery, and other consumer goods. Other benefits 
of working included enhancing marriage prospects, having something to do, a source of pride, having fun, and a way of learning skills for the future.

For many children, their experiences of school play a role: some described how they dislike school, for many reasons, one of the most frequently cited being that teachers beat them if they do not do well in their studies. One boy in Avanti described how he did badly at school, 'I am poor in studies. It is a waste ... if I study. If I continued to study... doing hard work will be later on... so I did not study... I think work is better for me.' Another boy, in Bhakrapet, described how he had completed his schooling, and started working on the farm:

What else can I do, sitting at home all the time, the day long? It is terribly boring and anyway we do need some money for the household. I started to work as I felt there was a need for some more money.... No one asked me to work and they wanted me to remain at home but I felt very bad remaining at home due to boredom. So I thought it would be better to work and so I started to go and work.

Other boys described how they chose to work. One boy in Avanti described how:

we ... feel like going to work... When we see all the others going to work, naturally we too would feel like going to work. No one would like to stay alone at home, .... if we go and work, it will be of immense help to us. ... if we go work, and are able to give our parents some money, they too would reciprocate by giving us say some 20 to 30 rupees for our expenses. What is the point of staying at home without working? It is not of any use and why should one stay at home without working?

Working is fundamental for family relationships. One boy described how he undertook a great deal of work on the family farm, because his father was living in Kuwait. He liked the work, and work was a source of pride. Another boy said, 'I am earning and giving to my parents, so I feel proud of that.' Work is also important for children's relationships with others in the community, and children's reputations. Work is part of being a 'good' child. One boy recounted how his mother had been told by others in the community

'Look, you are a blessed one. You are being looked after by your son and there is no need for you to work. He is not only earning but also taking care of you.' I felt very happy. I want to get a good name, still want to work hard and do better things.

Another boy described how working provided money that gave him status. He recounted how before he worked, 'nobody used to come to me; now since I have money, everybody comes, so I understood that everything will be there with the person who has money.' 
Work was seen as beneficial as a form of education in itself, because children learn work skills that they will need when they marry. For girls, prospective in-laws 'will certainly ask what we have learned in our parents' house'. As one girl said

After they get married and go, when there is more work then the work learned here will come in very useful, and if they go there without these skills, it would be very disadvantageous. So it is better to learn as they will be equipped for the future.

Additionally, work teaches children skills that are useful in general. One girl said, 'When we grow up, we can do the work.' One boy commented about his work: 'Since we have no education, this is useful.' When asked what he had learned by working from an early age, one boy commented, 'I can do things on my own. I need not depend on others. I feel like that.' In discussion, children in Bhakrapet mentioned that the suitable age for children to start work is 17-20 years. However, children talked about how occasional work was useful as training for full-time work and suggested that they should start earlier than that, so that they would be prepared for work by the time they are 18 or 20. 'Learning work should start early, or else the learning will never take place, because it is difficult to learn as adults.' On the whole, however, children hoped or planned to move out of agricultural work altogether. At present, they felt that agriculture is not viable for survival, it was not profitable because of crop-diseases, and it involves hard work in the hot sun.

When children work, they also socialise with friends, and have fun. One girl described how she preferred working on other people's fields, and she regretted working on her own on her family land.

Because I didn't get the opportunity of being with friends and being happy talking [about] different things and enjoying [myself]. When we are working on our land we are alone, whereas in the wage type of work, we get company... when I am in my own field, my eyes are always on the neighbouring fields....

One boy talked about how regular work made a person stronger.

In case one works regularly and consistently and works well, that person will not suffer from anything like fever or other ailments. He will not have any complications at all. .... He will be hale and healthy... if he goes to work as usual every day. ..If one remains at home without doing anything he will turn into a vegetable in course of time. He will become too weak and suffer from fever and other complications.

Children discussed what would happen if they were prohibited from working. For several children, being prevented from working would mean that they would have no food. One girl commented, 'We will not have rice, vegetables, and if we fall sick, they will not be able to take care of us. In every way, they face problems.' One boy commented 
I cannot imagine a life without working. Work means everything to me. Unless I work, we cannot run our house. .... We need to buy food to run our home... and I have to work to raise money to buy all these.

Another boy, in Bhakrapet, commented, 'If I completely stopped working, I would be as good as dead. There will not be any life left within me.'

On the other hand, not working or attending school means that some children 'just loaf around doing nothing. ... they are drinking and smoking beedis. They are very indulgent.' Not working was perceived as reducing one's marriage prospects. One boy commented:

What would happen to me if not working? My whole future is already spoiled. It would have been ruined even more. Studies are no more. I used to tend goats, even that is lost. Now if I lose [work] also, I would never get married.

\section{Experiences of agricultural work:}

Having decided to work, children undertake different operations at each of the stages of the life cycle of the various crops. Operations are clearly demarcated by gender, and a general agreement that the tasks done by boys and men are more physically risky and difficult. For example, in paddy, operations include preparing the field (ploughing), sowing, transplanting, weeding, spraying of fertilisers and pesticides, watering, harvesting, bundling, thrashing, collecting grain, and marketing. Of these tasks, men and boys are responsible for ploughing, watering, and thrashing, while women and girls are engaged in transplanting, weeding, harvesting, and bundling. The gender-based division of labour is found in almost all crops in both sites. Children's work on farms inevitably involves the risk of injuries and physical strain. Paddy is perceived as the most unpleasant, because it involves standing in water for planting, working in hot sun, working for low wages, and children felt they had to work in order to please the landlord. Table 1 below describes the different operations and parts of the body that are affected, and how children felt, and responded to risks. The content of the table was generated by children in group discussions, and some responses included risks at work beyond agriculture. Additional data are included from interviews. The intention is not to suggest that all children take the protective measures mentioned, but to illustrate their knowledge of what these might be.

[Table 1 near here]

Harm children reported fell into three broad themes. The first includes physical hazards, such as cuts scratches, and wounds while harvesting, cutting firewood, and ploughing; bruises from thorns and twigs while climbing trees and picking fruits; irritation from picking sunflowers; injuries from falling from the plough or from trees; snakebites and scorpion stings; and attacks on herders by animals. Another risk was 
of electric shocks from water pumps, and from electric fencing. The second category comprises healthrelated problems like itching, skin irritations, stomach ache, muscle and joint pains, headaches as a result of working in the sun, stomach upsets and nausea from pesticide exposure. In Bhakrapet, for example, boys described getting up at 3-4 a.m. to irrigate paddy fields, because the electricity supply is intermittent. This made them tired during the day. Third, psychosocial effects, such as disliking work or not wanting to work, feeling looked down upon by peers for not attending school, being teased for working by other children, and fearfulness and anxiety caused by work. Boys undertaking irrigation work at night described being afraid of evil spirits and ghosts. One boy described going to a traditional healer to ward off spirits, but said he couldn't work for two months. Children also mentioned the adverse effects of working on educational attainment, as one boy said, 'Our education will be spoiled... the children who go regularly to school score more marks than we do'

\section{Precautions taken against threats at work}

Children described numerous ways in which they tried to protect themselves at work. To avoid injuries while chopping wood, they undertook the task slowly and carefully. When moving stones, they spoke of carrying a little at a time to avoid injuries. When herding cattle, they carry axes, in case something attacks them, and they sleep together in groups, with dogs.

There would be ten of us sleeping together, and we can fight anything that intrudes...we would have dogs with us.... When in danger, they would start barking...

They described wearing long trousers and long-sleeved shirts when harvesting paddy to avoid scratches. If working with pesticides, children mentioned wearing a 'helmet' (protective face mask), that is, if it can be afforded. Children reported that not many people purchase them because they cost Rs 400 . Alternatively, they described tying or holding a cloth over the face but being aware that the pesticides may still affect their eyes. One boy said, 'I cover my mouth and nostrils with a mask, the way they cover themselves in hospitals.' Pesticide spraying is well-paid compared to other tasks, so it is an attractive but potentially dangerous task.

Children also described ways of avoiding injury in work other than agriculture that takes place in rural areas, probably helping or replacing parents in work undertaken as part of the National Rural Employment Guarantee Scheme. One boy described avoiding blisters while working with cement in construction work: 'I do not touch the mixed concrete with my bare hands.' Another boy described how his mother would not let him do the 'government jobs where they uproot trees... My mother says no... I 
might get hurt there... so she does not want me going there.' Children also mentioned wearing chappals (shoes) to protect themselves when walking or working on stony ground.

We wear those rubber soled shoes... the ones made with tyre material... everybody wears those only while working. So there is not much problem.

Some children described avoiding certain tasks. The most universally disliked work was related to paddy. One boy said he did not crop paddy, for fear of what might have happened (no children reported actual loss of fingers):

It's not because I cannot do that job. If we do that job, our fingers are likely to get injured... the sickle slips off our hands and lands on our fingers, and one of them gets chopped off ... I had been once to this job, and my fingers were injured. They were not completely chopped off .... From that time, I stopped doing that job.

A girl mentioned that she did not harvest paddy, because of the itching caused by the straw. 'That's why I don't go... I don't like it... we get it done by using wage labour.'

Another boy talked about being prohibited from spraying pesticides altogether.

Pesticides are very strong and pungent, so they [parents] will not let me do that. It is difficult, they will not allow me to do that work. They say, 'Look, don't do that. It is difficult and you cannot do that. In case you become unconscious... we have no money to get you cured. Don't do that.' That is what they said and so I don't do that job.

One girl described collecting oranges, but not lemons, because of the thorns, and not cutting paddy. Another boy mentioned that his mother only lets him do simple tasks, 'such as planting, picking lemons... specially lemon picking because it is just sitting under a tree and picking out lemons.'

Several examples show how children actively engage with the difficulties they face at work. This is not to suggest that these are acceptable risks, but to illustrate that they do have knowledge, experience, agency, and they are not simply passive victims in all this. For example, children explained that they were more likely to be injured at work if they lacked experience. Injuries happen mainly when they were new to the work, and these reduce as they get used to the tasks. One girl mentioned that the work 'caused wounds to legs... spade struck legs... when [we] go to work with half-knowledge about the work... things like that happen. Not now... I do better now... now I do it carefully... not much happens now.' Several incidents mentioned by children showed their initiative in dealing with their problems. When they were injured, children mentioned seeing a doctor, mostly on their own, or buying a pain killer or a fever tablet across the counter. While herding livestock in the forests, two boys in Bhakrapet 
reported fear of being attacked by bears, and described how the night stays in the forest are scary, but their strategy was to take dogs with them, and axes to ward off attacks.

\section{Linking micro-level data from children to international aims in child protection}

Thus, children describe a range of benefits of working, as well as the risks of not working. They often perceive work as something they choose to do rather than being forced into it, and work may be seen as a useful alternative to schooling, even though it can involve unpleasant drudgery. Children are involved in a range of agricultural activities, and they are aware of many of the hazards. While some children avoid tasks that are particularly hazardous and unpleasant, not all do. Few children suggest that avoiding work altogether is a solution to their problems. The decisions made by children and their families need to be taken into account if intervention is to be genuinely protective. What are the implications of this for thinking about hazardous labour, given that children (and their families) appear to be aware of the hazards they face and have some strategies for dealing with them?

In contrast to trying to eradicate the worst forms through the elimination of all child labour, pragmatic approaches grounded in children's experiences (Bourdillon et al. 2010 194-202), but also advocated by occupational safety and health experts (Fassa et al. 2010), may offer strategies for making work safer, not just for children, but also for adults. However, for pragmatic approaches to be accepted, an ideological shift would be needed among policy actors at international, national and state levels - away from the powerful but unrealistic rhetoric associated with child labour: children work on family farms in a number of activities that involve risk of harm in the most developed economies, and it has not proved possible to 'eradicate' this phenomenon entirely. Effective regulation, particularly in relation to specific risks such as pesticide use, could be developed, though in some instances children already appear to be prohibited from this informally (by parents).

There are also broader questions about the sustainability of farming, and the acquisition of knowledge and skills about agriculture, if children are forced to withdraw from work. Children do not seem to value agricultural work, although realistically, this is where the future is likely to lie for many of them. However, if children see no future in farming, this has implications for the sustainability of subsistence and market agriculture in developing countries. Enormous structural changes are needed before children's work is no longer required. In the meantime, in the current transition phase of agricultural development, it would be more respectful of children's dignity at work to recognise their activities, instead of devaluing their work and constructing it as a problem. Realistic questions also need to be asked 
about the proportion of the population that is likely to be able to escape farming through skills acquired at school.

Finally, we question the value of focusing solely on 'hazardous child labour'. It has long been acknowledged in rural sociology that in poor communities, traditional agriculture cannot be fully disentangled from practices of everyday life. Children's work is one resource among many that poor households draw upon in strategies to maintain their livelihoods. It is perhaps more helpful to focus on all household members and their livelihoods, instead of singling out children for study and intervention. Where daily survival is challenging, work is fundamental and cannot be considered separately from other aspects of daily life, and therefore the poverty behind it. Work is also a crucial aspect of children's social relationships and cannot be separated from inter-relationships within families and communities. Further, many health hazards in poor rural communities are not related to work, but to living conditions in general. Consideration must be given to what will be lost if children are removed from agricultural work altogether. Work may be integral to education, in the broadest sense, and may develop children's potential in the situations in which they live.

The common focus on either eliminating children's work altogether, or importing health and safety standards, is often based on the paternalistic assumptions that workers in developing countries (adults and children) do not know how to protect themselves. Data gathered from children about their experiences have shown that communities may develop their own methods of minimising harm at work, appropriately adapted to local circumstances. Children point to specific tasks, related to particular crops, and much can be learned from their experiences. However, further investigation is needed, because we cannot assume that poor rural communities are fully aware of all hazards that affect both children and adults alike, nor can we burden them with full responsibility for developing their own safer strategies. Research is therefore required to identify specific areas where safety needs to be improved, working alongside community norms instead of against them.

\section{Acknowledgements}

The authors thank the children, parents and others who participated in Young Lives research and the qualitative study reported here, the research team in Tirupati, and Gina Crivello, and Dr Vijay Kumar for helpful comments on an earlier draft of this paper, Gita Anand, and Daniel Vujcich for valuable research assistance. The authors also thank an anonymous reviewer. Young Lives is funded by Department for International Development (DFID). The qualitative study was funded by the Oak Foundation. The views expressed here are those of the authors and not those of DFID, Oak Foundation, Young Lives, or University of Oxford.

\section{Endnote}


The caste system is still extremely important in India in various spheres, not least politically. Scheduled Castes (SCs) are the lowest in the traditional caste structure and were earlier considered to be 'untouchables'. In rural Andhra Pradesh, SC colonies are located away from the main villages. SCs have been subjected to discrimination for years and had no access to basic services, including education. National legislation aims to prohibit 'untouchability' and discrimination. Backward castes or classes (BCs) are people belonging to a group of castes who are considered to be 'backward' in view of the low level in the caste structure. Scheduled Castes and Scheduled Tribes are traditionally disadvantaged communities.

\section{References}

Abebe, Tatek, and Sharon Bessell (2011) Dominant discourses, debates and silences on child labour in Africa and Asia Third World Quarterly, 32(4):765-786.

Bourdillon, Michael, Deborah Levison, Bill Myers, and BenWhite (2010) Rights and wrongs of children's work, Camden, N.J.: Rutgers University Press.

Clacherty, Glynis (2009) Hard work, long hours and little pay. Research with children working on tobacco farms in Malawi, Lilongwe, Malawi: Plan Malawi.

Cornwall, Andrea (1992) Body mapping in health RRA/PRA. RRA Notes, 16: 69-76.

Fassa, Anaclaudia , David Parker and Tom Scanlon (eds) (2010) Child labour. A public health perspective, Oxford, OUP.

Galab S, Vijay Kumar, Prudvikhar Reddy, Renu Singh and Uma Vennam (2011) The Impact of Growth on Childhood Poverty in Andhra Pradesh: Initial Findings from India Round 3 Survey Oxford: Young Lives

Gupta, Dipankar (2005) Caste and politics: identity over system. Annual Review of Anthropology 34:409427.

ILO (2011) Children in hazardous work. What we know. What we need to do. ILO/IPEC, Geneva.

ILO (2010) Road Map for achieving the elimination of the Worst Forms of Child Labour by 2016. www.ilo.org accessed $1^{\text {st }}$ Oct 2011.

Levison, Deborah and Marta Murray-Close (2005) Challenges in determining how child work affects child health. Public Health Reports, Nov-Dec 2005, 120: 614-620.

Morrow, Virginia and Uma Vennam (2010) Combining work and school: the dynamics of girls' involvement in agricultural work in Andhra Pradesh, India, Children \& Society, 24: 304-314

Ramanathan, Usha (2000) 'The Public Policy Problem: Child Labour and the Law in India' in Bernard Schlemmer (ed.) The Exploited Child, London: Zed Books

Shirol, S.V. (2000). Child labour: a rural reality. New Delhi, India: Classical.

Subbaraman, Subashini and Harol von Witzke (2007) 'An Overview of Child Labour in India'. in Gamini Herath and Kishor Sharma (eds) Child Labour in South Asia, Aldershot: Ashgate 
Woodhead, Martin (1999) Combating child labour: listen to what the children say. Childhood, 6(1): $27-$ 49. 